\title{
Retroviral Disease in Immunocompromised Patient Causing Varicella Encephalitis and TB meningitis -A Case Report
}

\author{
Vinushree BN ${ }^{1, *}$, Patchigolla Ganesh ${ }^{3}$, Sai Kumar Javvaji ${ }^{2}$ \\ ${ }^{1}$ Rajiv Gandhi University of Health Sciences, Karnataka College of Pharmacy, Bangalore, Karnataka, INDIA. \\ ${ }^{2} \mathrm{Sr}$. executive of Clinical Pharmacy at Rela Institute of medical center \\ ${ }^{3}$ Market analyst at Medsphere.
}

\begin{abstract}
The occurrence of opportunistic infection is largely seen in immunocompromised patients. Varicella infection is one such infection caused by Varicella Zoster Virus (VZV) - a human neurotropic virus which primarily presents as varicella or chickenpox and remains in dormant stage which reactivates showing as the leading cause for viral encephalitis. This case demonstrates a 32 years male patient who was presented with fever, chills, urinary retention, giddiness and vascular lesions on body. The patient was diagnosed as varicella zoster infection with the evidence of Polymerase chain reaction (PCR) of Cerebrospinal fluid (CSF) and started with ACYCLOVIR injection $500 \mathrm{mg}$. Later based on magnetic resonance imaging (MRI) scan results patient was found to have Tuberculosis meningitis and CD4 count human retrovirus (HIV) report reviled HIV. Gradually patient started developing rashes on genitals diagnosed as Verruca Vulgaris. The patient was on symptomatic therapy with anti tuberculoid (AKT 4 kit) with plan to start Anti-retroviral therapy (ART) after 2 weeks.
\end{abstract}

Key words: Varicella zoster virus, Encephalitis, Immunosuppressed, Meningitis, Tuberculosis, Verruca vulgaris.

\section{INTRODUCTION}

Varicella Zoster Virus (VZV) is an alpha herpes virus belongs to Alphaherpesvirinae family which infects humans worldwide. ${ }^{1}$ Varicella occurs in childhood as a primary infection with varying clinical manifestations. Children below 10 years of age are affected with primary infection and in adults they account up-to $7 \%$.

The virus then enters the dormant stage in the ganglia of cranial nerves, dorsal route and in autonomic nervous system. ${ }^{2}$ In adulthood reactivation of the virus is observed with aging or when there is decline $\mathrm{T}$ - cell-mediated immunity affecting central or peripheral nervous system causing number of complications of neurological syndromes like encephalitis, herpes zoster, vasculopathy, myelopathy and cerebellitis., Inpatient above age of 80 the incidence varies from 2-4.6 from 1000 person-years to 10 per person-years. The severity of clinical manifestation ranges from mild, self-limiting cutaneous infection to encephalitis with mortality rate of $12 \%-15 \% .{ }^{5}$ Varicella zoster virus primarily causes cutaneous rashes but, in some cases, neurological symptoms may occur with or without rashes which leads to delayed or wrong diagnosis. ${ }^{1}$ In such cases, detection of DNA or analysis for specific antibodies by PCR technique can be done. ${ }^{5}$

The following case report is about an immunocompromised male patient of 32 years who came with avascular lesions in the body, later diagnosed with varicella zoster infection leading to encephalitis, HIV and Verruca Vulgaris.

\section{CASE REPORT}

A 32-year male patient was admitted to the hospital who was an alcoholic and smoker, weighing $45 \mathrm{~kg}$, he showed signs of generalized weakness. He was presented with fever associated with chills, giddiness, and difficulty in walking, urinary retention
DOI: 10.5530/ijopp.14.3.42

Address for

correspondence:

Vinushree BN

Doctor of Pharmacy, Rajiv Gandhi University of Health Sciences, Karnataka College of Pharmacy, Bangalore, Karnataka, INDIA. Email Id: vinushree.bn27@gmail. com

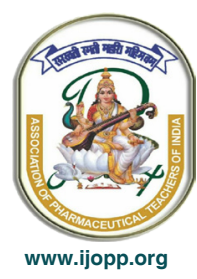


and vascular lesions on the body. History of skin eruptions (varicella zoster infection 10 days before was found). Romberg's test was conducted to check the motor coordination and was found positive suggesting encephalitis. He was treated with anti-viral drug ACYCLOVIR 500mg thrice a day (TID). The patient's leukocyte count (13.5) was high indicating a possible viral infection and neutrophils count (81.4) which is significant of bacterial infection and also pus cells in urine (6-8) was found suggestive of urinary tract infection. Sodium and magnesium levels were slightly low. MRI whole spine report was suggestive of lepto-meningitis because of abnormal meningeal enhancement along surface of spinal cord and cauda equine nerve roots and CSF of Gram stain showed negative suggesting of TB Meningitis. $\mathrm{KOH}$ preparation fungus test resulted as not seen ruling out psoriasis and eczema. INDIAN INK test was carried out to rule out fungal infection which showed negative results. Acid-fast bacilli (AFB) suggested that it is not a bacterial infection and Gene Xpert test was reported as not detectable. Later patient was advised to check for HIV and was treated with: Tab. Acyclovir 500mg TID (for varicella), Syrup Lactulose as SOS medication INJ. Thiamine $100 \mathrm{mg}$ TID (as Vitamin $\mathrm{B}_{12}$ supplement), INJ. Neurobion Forte 1ampule is a mixture of six Vitamin $\mathrm{B}$ (thiamine $10 \mathrm{mg}+$ riboflavin $10 \mathrm{mg}+$ nicotinamide $45 \mathrm{mg}+$ calcium pantothenate $50 \mathrm{mg}+$ pyridoxine $3 \mathrm{mg}+$ cobalamin $15 \mathrm{mcg}$ ) once in afternoon to treat (Vitamin deficiency), INJ. Ceftriaxone $1 \mathrm{~g}$ BID (to treat meningitis). CSF analysis results is shown in Table 1.

PCR of CSF detected Varicella zoster virus confirming infection. HIV report revealed HIV 1 and 2 ab, HIV 1 and 2, HIV Tridot reactive suggesting HIV infection. The patient had complaints of headache, fever and ataxia giant was positive. CD4 analysis suggested that the patient is at high risk of HIV as shown in Table 2.

Patient in addition to the earlier treatment, continued with, TAB. fluconazole $200 \mathrm{mg}$ once in afternoon (to treat fungal infection as prophylaxis), TAB. Bactrim DS (sulfamethoxazole + trimethoprim) 1 tab BID to treat (bacterial infection). The serological test was positive for retroviral disease (RVD) and confirmed. It was suggested to send serum cortisol to analyze probability of autonomic function and the result was 15.06 (0.4958.6) normal. LACTIFIBER POWDER-TSP-BID was added to the treatment.

The patient has not passed urine and on opinion of urologist KIDNEY, URETER and BLADDER (KUB) $\mathrm{X}$-ray was taken. Urinary inconsistency and rashes on genitals were seen which was diagnosed as Verruca Vulgaris. Further advice was to continue treatment along with Cap. SILDOSIN 4mg 0-0-1 to treat benign prostatic hyperplasia.

Verruca vulgaris is a viral infection caused by Papillomavirus is seen mostly in immunocompromised patients. The clinical manifestations are scaly papules or nodules seen of size varying from less than $1 \mathrm{~mm}$ to more than $1 \mathrm{~cm}$ shown in Figure 1.

The final diagnosis of the case was Varicella encephalitis, TB meningitis, Verruca Vulgaris, Retroviral disease and Urinary tract infection.

Patient was discharged with TAB. ACYCLOVIR -500mg -1-1-1 - , SYP LACTULOSE2 TSP SOS, TAB. FLUCONAZOLE $200 \mathrm{mg}$ 0-1-0 -, TAB. BACTRIM DS 1TAB - 1-0-1, LACTIFIBERPOWDER2 TSP - 1-0-1

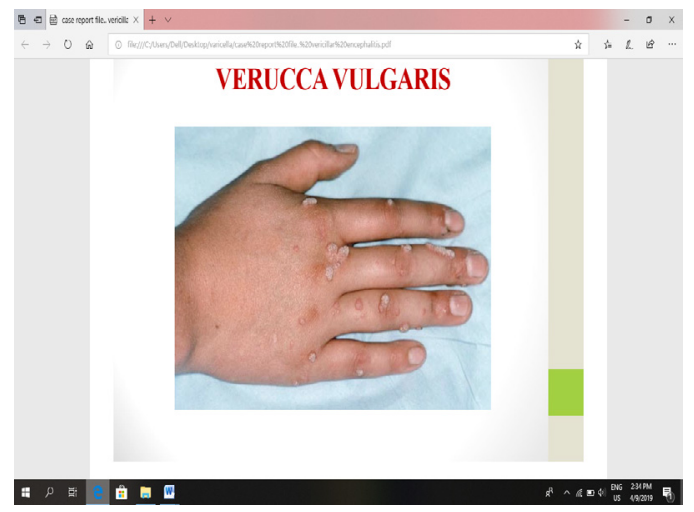

Figure 1: Showing papilloma virus infection.

\begin{tabular}{cc}
\hline Table 1: CSF Analysis. & \\
\hline Parameter & Value \\
\hline Appearance & Colorless \\
Clear lymphocytes & $100 \%$ \\
Cryptogen antigen & Negative \\
Glucose & $83 \mathrm{mg} / \mathrm{dl}(45-80)$ \\
Protein & $179 \mathrm{mg} / \mathrm{dl}(20-40)$ \\
Chloride & $111(116-127)$ \\
\hline
\end{tabular}

Table 2: CD4 analysis.

\begin{tabular}{clc} 
Parameter & Normal value & Observed value \\
\hline \%CD3 + CD4 (T HELPER) & $26-48$ & 11.0 \\
\%CD3 + CD8 (T & $18-41$ & 72.67 \\
$\begin{array}{c}\text { SUPPRESOR) } \\
\text { ABS CD4 + Lymphocyte } \\
\text { count }\end{array}$ & $354-1100$ & 185 \\
$\begin{array}{c}\text { ABS CD8 + Lymphocyte } \\
\text { count }\end{array}$ & $192-980$ & 1228 \\
CD4/CD8 RATIO & $0.57-2.03$ & 0.15 \\
\hline
\end{tabular}


CAP. SILODOSIN-4mg -0-0-1-, ONABETCREAM (sertacalazole) - 1-0-1 -, PODOWART POWDER ONCE A WEEK- , AKT4 - 1 STRIP - DAILY - (anti TB), TAB. BENADON (pyridoxine) - $40 \mathrm{mg}-1 / 2-0-0$, 40\% SALICYLIC ACID ointment, AKT4 kit -1 -strip daily and Plan to start Anti-viral therapy after 2 weeks.

\section{DISCUSSION}

Varicella is seen in two phases, primarily in children (as chickenpox) below age of 10 and reactivation later during adulthood. Reactivation of varicella zoster infectioncausing neurological symptoms is more commonly seen in adults and immunocompromised patients. From the dorsal root ganglia, the VZV reactivates and before the onset of central nervous system (CNS) symptoms it often shows disseminated skin lesions. ${ }^{6}$ On the other hand, vascular and parenchymal infections are rarely caused in absence of cutaneous lesions with VZV. ${ }^{7}$ The most common neurological complications seen in immunocompromised patient infected with VZV is vasculopathy, encephalitis, myelitis, ventriculitis, meningitis and leukoencephalopathy.

Encephalitis is one of the serious complications of VZV infection and mostly reported in immunocompromised patients and rare in immunocompetent patient; when it occurs in a healthy patient it is characterized by disseminated rashes with some neurological symptoms. ${ }^{8}$ The pathogenesis of varicella zoster virus replication causing encephalitis is uncertain while few studies suggest post-infectious demyelinating process but others say direct viral cytopathology. ${ }^{9}$ Encephalitis can be classified into three types: 1) large vessel vasculopathy which is prominently seen in adult immunocompetent patient which may present with focal neurological deficit consistent with stroke 2) Small vessel vasculopathy is more prominent in immunocompromised patients and presents with symptoms like headache, nausea, seizure, mental status changes 3) ventriculitis is due to infection of periventricular of ependymal cells resulting in giant disorder or hydrocephalus. ${ }^{10,11}$

Primarily there is increased lymphocyte and neutrophils increase suggesting infection. The CSF pressure is abnormal with elevated pressure, increased protein $(179 \mathrm{mg} / \mathrm{dl})$ and glucose levels $(83 \mathrm{mg} / \mathrm{dl}) .{ }^{9}$ The confirmation of the diagnosis, in this case, was established by observing viral-specific DNA sequence in cerebrospinal fluid by polymerase chain reaction (PCR) amplification which is considered to be Gold standard method and far better than confirmation done by specific IgG antibodies produced intrathecally. VZV DNA detection by PCR has 95\% specificity and 30\% sensitivity. For diagnosis of VZV with predictive value of PCR in CSF, the clinical presentation (CNS symptoms) should also be taken into account along with concurrent infections. ${ }^{12}$ The mortality rate of VZV infection is $5-10 \%$ where majority of them recover completely. There is as such established prospective anti-viral therapy for varicella encephalitis and therefore Acyclovir is used intravenously which is well tolerated by patients and found to be safe. It is excreted through the kidney and hence dose adjustment is necessary.

Superinfection of skin eruptions in varicella by Staphylococcus aureus and Streptococcus pyrogens leading to toxic shock syndrome can also be reported. ${ }^{13}$ Hence Acid-fast bacilli test to check for bacterial infection was done and showed negative. TB meningitis is a deadly disease seen mostly in people with pulmonary $\mathrm{TB}$, immunocompromised patients, malnutrition, poverty, crowded areas mostly in endemic areas. But TB in immunocompetent is very less. ${ }^{14} \mathrm{CSF}$ analysis is considered to be sensitive test for diagnosis of $\mathrm{TB}$ meningitis which includes increases protein and low level of glucose, predominant pleocytosis. However, this patients CSF finding did not match the typical findings but there were increased levels of neutrophil count (81.4) and MRI whole spine showed suggestive of TB meningitis. ${ }^{14,15}$ The patient was treated with ceftriaxone intravenously Q12 hourly, in addition injection Thiamine and Neurobion forte was given as Vitamin supplement.

There are three types of human retroviruses human T cell lymphocytic virus type 1 (HTLV -1$)$, human immunodeficiency virus type 1 (HIV -1) and (human immunodeficiency type 2 (HIV -2). HTLV-1 is an etiological agent of leukemia of adult T cell. HIV 1 and 2 are responsible for acquired immune deficiency syndrome (AIDS) worldwide. ${ }^{16}$

HIV 1 is more virulent and spread easily than HIV 2 and it causes wasting and neurological syndrome including myelopathy, neuropathy and dementia. HIV 2 is less prevalent and less pathogenic type mainly seen is western America. It is believed that dysfunction of immune system is caused by some virus infections like influenza, herpes simplex virus, cytomegalovirus and VZV. Thus, AIDS occurs as last virus illness that suppresses the responsiveness of immune system. HIV 1 usually grows in cell and destroy them ultimately that is virus grows selectively in cells and collapses the immune system by destroying the CD 4 cells ( $T$ lymphocytes), other cells like macrophages, monocytes, neural and dendrite cells and endothelial cells. ${ }^{16}$

HIV infection can be diagnosed by detecting HIV 1 and 
2 antibodies by immunoassay (ELISA) and HIV 1 and 2 tridot test which was found to be reactive in this patient. ${ }^{17}$ HIV is mainly diagnosed based on CD 4 cells count, decrease in the CD4 count is indicative of HIV infection which was observed in this case also (\%CD3 and CD4 - 11.0) and (ABS CD4+ Lymphocyte count-185) thus confirmed as HIV infection. On conducting serological test for the retroviral disease it was found to be positive.

In an immunocompromised patient chance of infections (viral, bacterial and fungal) are more and hence along with anti-viral therapy, antibiotics and antifungal treatment will be started as prophylaxis. Though INDIAN INK test showed negative for fungal infection and $\mathrm{CBC}$ after few days were normal, TAB. Flucanazole $200 \mathrm{mg}$ and TAB. Bactirm DS for bacterial infection were added to the treatment as prophylaxis.

Verruca Vulgaris (VV) or a wart is caused by Human papillomavirus (HPV) of pappilomaviridae family which is seen in humans and few other species also. They cause benign proliferation of skin and mucosa and are highly host specific and for instance infects humans only. Based on the sequence of viral L1 gene the HPV is categorized into 3 types shown in Table $3 .^{18}$

Clinical manifestation of verruca Vulgaris includes rough, scaly nodules or papules seen on skin. Size of nodules varies from less than $1 \mathrm{~mm}$ to more than $1 \mathrm{~cm}$ shown in Figure 1. ${ }^{18,19}$ In this case rashes were found on genital organs whose symptoms were suggestive of VV. patient had not passed urine and complaint of urinary incontinence was seen which was treated with Capsule. Silodosin $4 \mathrm{mg}$ at night. Treatment for VV depends on the age of patient, immunological condition, duration and extent of lesions. Some common approaches for treatment are chemotherapeutic agents, cyto-destructive methods, immunotherapy and anti-viral therapy. According to report by Mona, suggests that $40 \%$ salicylic acid ointment showed good results. ${ }^{18}$

\section{Table 3: Types of HPV.}

\begin{tabular}{cc} 
Categories & HPV types \\
\hline Cutaneous (non- genital) & $1,2,3,4$ \\
Genital mucosa & $6,11,16,18$ \\
$\begin{array}{c}\text { Epidermodysplasia } \\
\text { verruciformis }\end{array}$ & 8.18 \\
\hline
\end{tabular}

\section{CONCLUSION}

Varicella causes typical symptoms which can easily dragonized by the clinician. But in some cases, it presents with unusual symptoms and causes serious complication.
In case of immunocompromised chances of infections (bacterial, fungal and viral) are more and prophylaxis treatment is always necessary. In this case, encephalitis and meningitis has occurred as complication of varicella and since patient is HIV positive urinary tract infection and other opportunistic infections are seen. Symptomatic treatment along with anti-viral is given and plan to start anti-viral therapy for the retroviral disease after 2 weeks.

\section{ACKNOWLEDGEMENT}

The author(s) would like to acknowledge, Karnataka College of Pharmacy and Bangalore Baptist Hospital, Bengaluru, Karnataka, India for providing an institutional research platform and necessary facilities.

\section{CONFLICT OF INTEREST}

The authors declare that they have no conflict of interests regarding the case report. There was no difference of opinion from the patient as well as the organization.

\section{ABBREVIATIONS}

AFB: Acid Fast Bacilli; AIDS: Acquired immune deficiency syndrome; AKT: Anti tuberculoid kit; ART: Anti retro-viral therapy; BID: Twice daily; CBC: Complete blood count; CD4: Cluster of differentiation; CNS: Central nervous system; CSF: Cerebrospinal fluid; DNA: Deoxyribonucleic acid; ELISA: Enzyme linked immunosorbent assay; HIV: Human immune retro virus; KOH: Potassium oxygen and hydrogen; KUB: Kidney urethra and bladder; HTLV-1: Human T cell lymphocytic virus type; HTLV-2: Human T cell lymphocytic virus type 2; HPV: Human papillomavirus; MRI: Magnetic resonance imaging; PCR: Polymerase chain reaction; RVD: Retro viral disease; TB: Tuberculosis; TID: Thrice daily; UTI: Urinary tract infection; VZV: Varicella zoster virus; VV: Verruca Vulgaris.

\section{SUMMARY}

It is well known fact since ages that immunocompromised patients are more prone to opportunistic infections (bacterial, fungal and viral) like Varicella zoster, tuberculosis, meningitis. The case report is about a male patient who initially reported with fever, chills, urinary retention and vascular lesions on the body. Patient was initially focused on the vascular lesions and was diagnosed as varicella infection with the evidence of PCR report. Further patient was subjected to MRI scan and based on reports TB meningitis was reviled. Encephalitis was also seen as complications of varicella. With the KUB test it was found that patient has verruca vulgaris urinary tract infection. With the cluster if infections seen patient 
was finally subjected to check for CD 4 count which was evident to HIV positive infection showing the origin of infection. Patient was treated symptomatically along AKT4 kit for tuberculosis and plan to start ART after 2 weeks.

\section{REFERENCES}

1. Broucker DT, et al. Acute varicella zoster encephalitis without evidence of primary vasculopathy in a case-series of 20 patients. Clinical Microbiology and Infection. 2012;18(8):808-19.

2. Carey RA, Chandiraseharan VK, Jasper A, et al. Varicella zoaster virus infection of the central nervous system - 10 year experience from tertiary care hospital in south India. Ann Indian Acad Neurol. 2017;20(2):149-52.

3. Steiner I, Kennedy PGE, Pachner AR. The neurotropic herpes viruses: Herpes simplex and varicella-zoster. Lancet Neurol. 2007;6(11):1015-28.

4. Gershon AA, Gershon MD, Breuer J, Levin MJ, Oaklander AL, Griffiths PD. Advances in the understanding of the pathogenesis and epidemiology of herpes zoster. J Clin Virol. 2010;48(Suppl 1):S2-7. doi:10.1016/S1386-6532(10)700020 .

5. Skripuletz T, Pars K, Schulte A, et al. Varicella zoster virus infections in neurological patients: A clinical study. BMC Infect Dis. 2018;18(1):238 Published 2018. doi:10.1186/s12879-018-3137-2

6. Gilden DH, Kleinschmidt-DeMasters BK, LaGuardia JJ, et al. Neurologic complications of the reactivation of varicella-zoster virus. $\mathrm{N}$ Engl $\mathrm{J}$ Med. 2000;342(9):635-45

7. Toledo PV, Pellegrino LN, Cunha CA. Varicella-zoster virus encephalitis in an AIDS patient. Braz J Infect Dis. 2004;8(3):255-8.
8. Jordan CD, Korley F, Hamade B. Varicella zoster virus encephalitis in a immunocompetent patient with out RASH. American Journal of Emergency Medicine. 2016;34(11):2257.e1-2.

9. John W, Varicella-Zoster G. Virus: Atypical Presentations and Unusual Complications. The Journal of Infectious Diseases. 2002;186(Supplement_1):S91-8.

10. Kleinschmidt-DeMasters BK, Amlie-Lefond C, Gilden DH. The patterns of varicella zoster virus encephalitis. Hum Pathol. 1996;27(9):927-38.

11. Elwir SM, Shaffer CC, Arvan SW, Kuperman EF. Disseminated Varicella Zoster Virus Infection with Encephalitis in a UC Patient Receiving Infliximab. Gastroenterol Hepatol. 2013;9(1):54-6.

12. Low LL, Vasanwala FF, Suhail SM. Varicella encephalitis and pneumoniaina patient with end stage renal failure. Asia Pac Fam Med. 2014;13(1):4.

13. Aebi C, Ahmed A, Ramilo O. Bacterial complications of primary varicella in children. Clin Infect Dis 1996;23(4):698-705.

14. Khanna SR, Kralovic SM, Prakash R. Tuberculous Meningitis in an Immunocompetent Host: A Case Report. Am J Case Rep. 2016;17:977-81. Published 2016. doi:10.12659/ajcr.900762.

15. Tan JL, Nordin S, Besari AM. Rare Clinical Presentation of Tuberculous Meningitis: A Case Report. Malays J Med Sci. 2017;24(5):119-23. doi:10.21315/ mjms2017.24.5.14.

16. Wainberg MA, Dascal A, Mendelson J. Anti-retroviral strategies for AIDS and related diseases. Canadian Journal of Infectious Diseases and Medical Microbiology. 1991;2(3):121-8.

17. Fearon DM. Medical Microbiology, Canadian Blood Services, 67 College Street, Toronto, Ontario M5G 2M1. 2005 Telephone 416-313-4598, fax 416-974-9757,

18. Pandurengan K, Chidambaram NRMRSTK. Giant Verruca Vulgaris-Rare Presentation. The Internet Journal of Dermatology. 2010;8(2).

19. Bacaj P, Burch D. Human Papillomavirus Infection of the Skin. Archives of Pathology and Laboratory Medicine. 2018;142(6):700-5. 